\title{
Education and training in a model of endogenous growth with creative destruction
}

Citation for published version (APA):

van Zon, A. H., \& Antonietti, R. (2005). Education and training in a model of endogenous growth with creative destruction. UNU-MERIT, Maastricht Economic and Social Research and Training Centre on Innovation and Technology. MERIT-Infonomics Research Memorandum Series No. 011 https://doi.org/10.26481/umamer.2005011

Document status and date:

Published: 01/01/2005

DOI:

10.26481/umamer.2005011

Document Version:

Publisher's PDF, also known as Version of record

\section{Please check the document version of this publication:}

- A submitted manuscript is the version of the article upon submission and before peer-review. There can be important differences between the submitted version and the official published version of record.

People interested in the research are advised to contact the author for the final version of the publication, or visit the DOI to the publisher's website.

- The final author version and the galley proof are versions of the publication after peer review.

- The final published version features the final layout of the paper including the volume, issue and page numbers.

Link to publication

\footnotetext{
General rights rights.

- You may freely distribute the URL identifying the publication in the public portal. please follow below link for the End User Agreement:

www.umlib.nl/taverne-license

Take down policy

If you believe that this document breaches copyright please contact us at:

repository@maastrichtuniversity.nl

providing details and we will investigate your claim.
}

Copyright and moral rights for the publications made accessible in the public portal are retained by the authors and/or other copyright owners and it is a condition of accessing publications that users recognise and abide by the legal requirements associated with these

- Users may download and print one copy of any publication from the public portal for the purpose of private study or research.

- You may not further distribute the material or use it for any profit-making activity or commercial gain

If the publication is distributed under the terms of Article $25 \mathrm{fa}$ of the Dutch Copyright Act, indicated by the "Taverne" license above, 


\section{MERIT-Infonomics Research Memorandum series}

Education and Training in a Model of Endogenous Growth with Creative Destruction

Adriaan van Zon \& Roberto Antonietti

2005-011

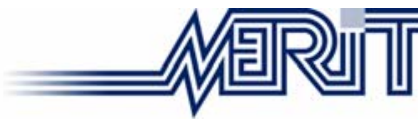

MERIT - Maastricht Economic Research Institute on Innovation and Technology

PO Box 616

6200 MD Maastricht

The Netherlands

T: +31433883875

F: +31 433884905

http://www.merit.unimaas.nl e-mail:secr-merit@merit.unimaas.nl

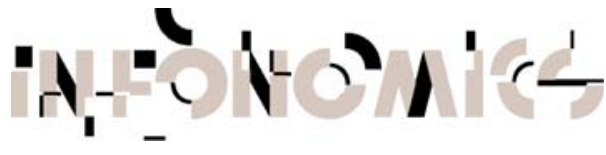

International Institute of Infonomics

c/o Maastricht University PO Box 616

6200 MD Maastricht

The Netherlands

T: +31 433883875

F: +31 453884905

http://www.infonomics.nl e-mail: secr@infonomics.nl 
Education and Training in a Model of

\title{
Endogenous Growth with Creative Destruction
}

\author{
by \\ Adriaan van Zon \\ and \\ Roberto Antonietti
}

(Second draft, March 2005) 


\title{
Education and Training in a Model of Endogenous Growth with Creative Destruction
}

\author{
Adriaan van Zon* and Roberto Antonietti** \\ First draft September 2004; second draft November 2004
}

Keywords: education, on-the-job training, technology adoption, wear and tear effect, endogenous growth

JEL Classification: J24, O31, O41

\begin{abstract}
By formulating an endogenous growth model that combines elements from Romer (1990), Aghion and Howitt (1992), and van Zon and Yetkiner (2003), the present paper studies the contribution of education and training on economic growth through their impact on the rate of innovation. The article addresses two main issues. The first is the optimum provision of on-thejob training necessary to be able to adopt, and adapt to new technologies. The second is the impact of both formal education and on-the-job training on the innovative capacity of an economic system that is the ultimate cause of output growth. In our set-up, education enhances R\&D activities and lowers adjustment costs to new technologies, thus facilitating their adoption, while on the other hand on-the-job training ensures the possibility to implement the new coming technologies and reap all the related future profits.

We assume that the adoption of a new technology consists of two periods, i.e. the training phase during which newly hired workers acquire the right amount of know how in order to become familiar with the specific new technology, and the implementation or production phase in which profit flows arise for firms and in which the cost savings that can be realized arise from productivity increases in the previous phase. By extending the training phase, entrepreneurs run a greater risk of shortening the production phase for a given arrival rate of new technologies that progressively erode the profit flows obtained from existing technologies.

The paper shows first that it is possible to find a profit-maximizing, endogenously determined, amount of training that depends on the workers' educational attainment. Thus, a situation in which better educated workers may be disproportionately selected for training issues is possible, especially in times of rapid technological change. However, the paper also shows that a non-linear relationship between education and technological change (and growth) exists, so that an increase in the formal level of education can even result in a reduction in the rate of growth. The reason for this is the increase in creative destruction that raises 'technology adoption costs' in terms of output foregone during re-training spells that arrive at a faster rate. The results offer some insights that are interesting from an education policy perspective.
\end{abstract}

\section{Acknowledgements}

We would like to thank Theo Dunnewijk, Thomas Ziesemer and Lex Borghans for their useful comments on the preliminary version of this paper. Roberto Antonietti is particularly grateful to Gilberto Antonelli, Alessandro Romagnoli, Giuseppe Vittucci Marzetti and Sandro Montresor for their valuable advices during the PRIN workshop on "Dynamic Capabilities Between Firm's Organization and Local Production Systems”, Lecce (Italy), 25-26 June 2004. The usual disclaimer applies.

* Department of Economics and MERIT, Maastricht University. P.O. Box 616 - 6200 MD Maastricht (The Netherlands). E-mail: Adriaan.vanZon@merit.unimaas.nl.

** Alma Mater Studiorum - University of Bologna - Department of Economics. Strada Maggiore, 45 - 40125 Bologna (Italy). E-mail: antonietti@spbo.unibo.it. 


\section{Introduction}

The purpose of the paper is to study the contribution of education and training to economic growth through their impact on the rate of innovation, by formulating an endogenous growth model that combines elements from Romer (1990), Aghion and Howitt (1998) and van Zon and Yetkiner (2003). The model takes the endogeneity of firms' training decisions into account and addresses two main issues. The first concerns the profit-maximizing provision of workplace training necessary to be able to adopt, and adapt to, new technologies. The second concerns the impact of formal education and on-thejob training on the innovative capacity of an economic system that is the ultimate cause of output growth. In our set-up, education and employerprovided training fulfil two different functions: general education programmes, whose costs are mainly borne by individuals, households and public administrations, increase the opportunities for future research and lower adjustment costs to new technologies, thus facilitating their adoption, while firm-specific training programmes ensure the profitable adoption of the new technologies.

Our setting links the labour economics literature on education and training and the endogenous growth literature on human capital formation as the primary cause of productivity growth. So far, training, and especially its interaction with formal schooling, has hardly been investigated in the growth literature. The reason why we have chosen to pursue this combination of different strands of literature is that, since the 1980's, massive shifts have occurred in skill requirements in the workforce as a result of rapid technological progress and skill-biased technical change (David, 1990; Acemoglu, 1996, 2002; Lopez-Bassols, 2002; Bartel et al., 2003). This emphasizes at least the practical importance of the availability of skills through education and training for economic growth. As Breshnahan et al. state: "The shift toward more skilled workers appears to have accelerated in the last 25 years relative to 1940-1973, especially over the period 1980 until the mid-1990s. Over this period, demand has strongly shifted from low-and middle-wage occupations and skills toward highly rewarded jobs and tasks, those requiring exceptional talent, training, autonomy, or management ability" (2002, p. 339).

With the breakthrough of ICTs in the 1990s as a general purpose technology (GPT), many occupations and professions now require skills that are a mix of studies that are privately undertaken and which are necessary to enter certain segments of the labour market, and skills which have been acquired on the job. Therefore, formal education is not sufficient anymore for explaining international differences in growth performances: whenever specialization matters, on-the-job training, at least, plays a crucial role besides schooling.

\subsection{New technology and training: an overview of the literature}

The way in which an economy responds to the arrival of a new major technology has been analyzed both at microeconomic and at macroeconomic level. At microeconomic level, the first attempts emphasizing the importance of education and training investments in relation with technological change are the ones by Nelson and Phelps (1966) and Mincer (1962, 1989). Besides these 
seminal contributions, we have also to consider the recent literature borne around the issue of new technology adoption, the standard theory of the firm and the relative choices in terms of human capital investments and organizational changes (Pencavel, 1972; Parsons, 1990; Kalaitzidakis, 1997, Gander 2002). Outside the standard theory of the firm an important contribution which analyzes the interactions between the creation of specific human capital and the destruction of this same human capital engendered by the technological and organizational change is the one by Antonelli and Maggioni (1997). In their model, this relationship is non-linear and shows some features associated with the 'catastrophe theory'. In particular, as the rate of technological change increases, the long-term equilibrium of a worker's specific human capital diminishes. After a certain threshold is reached, this same worker will no longer be able to accumulate human capital through work and will therefore be eliminated from the productive process.

At macroeconomic level, the way in which an economic system responds to the arrival of a new major technology has been described in the growth literature focusing on general purpose technologies (GPTs). In that literature researchers have been mainly interested in investigating the role played by mechanisms like secondary innovations, diffusion, and learning by firms (Greenwood and Yorokoglu, 1997; Helpman and Trajtenberg, 1998a, 1998b; Aghion and Howitt, 1992, 1998). In particular, in their models Aghion and Howitt put the attention on the role played of R\&D activity on economic growth, and on the process of Schumpeterian creative destruction activated by fast technological change on output growth. In their setup, growth is generated by a stochastic sequence of quality improving innovations that result from uncertain research activities. The main characteristic of vertical innovation is that new inventions make old technologies or products obsolete. This obsolescence, also called 'creative destruction', implies a negative relationship between current and future research, which results in the existence of a unique steady-state equilibrium and also in the possibility of cyclical growth patterns. The model leads to the conclusion that if the rate of technological progress in plants is very fast, then plants will have a short lifetime and hence the proportion of workers released every period will be high. The rapid flow of workers into unemployment will generate a high steady-state unemployment rate.

In addition, the faster rate of plant obsolescence reduces the payout period to a firm's investment in plants. By discouraging the creation of the new plants that are the source of new job opening, it thus tends to reduce the jobfinding rate in the economy, leading to a higher steady-state unemployment rate. We can call this effect 'indirect creative destruction' (Aghion and Howitt, 1998, p. 143).

Recently, Heplman and Rangel (1999) and Krueger and Kumar (2002), focus the attention on a new mechanism, the interplay between technological change and two types of human capital: technology-specific experience or vocational education and training. The first of the two models show that technological change requiring more education and training (so that a technology-education complementarity arises), like computerization and ICTs diffusion, necessarily produces an initial slowdown, whereas technological change requiring less education and training (technology and education are substitutes), like the move from artisan shop to the factory, can produce either a boom or a bust. The second, instead, show that economic systems whose 
policies favour vocational education, like European Union, will grow slower than systems favouring general education, like the US, this gap increasing with growth rate of available technology. 


\subsection{The interaction between general education and specific training in adopting new technologies: theory and evidence from the literature}

The literature on labour economics since the $1960 \mathrm{~s}^{1}$ has often stressed the importance of activities like training, learning by doing and experience in the process of human capital accumulation, both at the individual and at the firm level. For, as early as 1962, Mincer states that formal school instruction is neither an exclusive nor a sufficient method of training the labour force. Graduation from some level of schooling does not signify the completion of a training process. It is usually the end of a more general and preparatory stage, and the beginning of a more specialized and often prolonged process of acquisition of occupational skills, after entry in the labour force. This second stage, training on the job, ranges from formally organized activities such as apprenticeships and other training programs to informal processes of learning from experience.

According to Acemoglu:“(T)raining is important when new technologies are adopted, or in the process of a radical change in the environment, for example the shift from low to high skill jobs taking place in most OECD countries today" (1996, p. 446).

The importance of the distinction between formal education and workplace training has been also empirically stressed in many research studies. The first we mention was carried out in 1979 and concerned workers in Germany (Pischke, 2001), while the second and the third ${ }^{2}$ concerned Canadian workers in 1989 and 1993 respectively. Moreover, we can also mention a fourth source of evidence: the Eurostat's Continuing Vocational Training Survey (CVTS) (OECD, 2003).The main conclusions from that studies are that: i) the most common channel through which manufacturing workers obtain the most important skills for the labour market is continuous formal on-the-job training; ii) the most important place where they received the most useful skills for the labour market is the firm, the workplace, the second being school and higher education institutions. Other indicative data in this field are the ones provided by the BLS Survey of Employer-Provided Training (Frazis et al., 1995), the US Educational Quality of the Workforce National Employers Survey (EQW-NES) and Lynch (1995). According to these analyses, companies provide training because firm-specific skills are needed, because of changes in technology, and to retain employees; not only, but basic skills are often easier to learn when taught in the context of a job.

While there is ample empirical evidence that the distinction between education and on-the-job training is important in shaping and improving individuals' skills endowments, the logical next question is whether these types of training are really substitutes or complements. The positive links discussed above between training and technical change on the one hand and education and technical change on the other, suggests such a positive correlation also for education and training. A direct, albeit partial, answer to this question also comes from Mincer (1962), who recognizes that the degree of substitutability

\footnotetext{
${ }^{1}$ We are referring to the 'human capital revolution' driven by the Chicago School (Lewis, Mincer, Becker) even if we should always keep in mind that the very seminal contribution on this field has been provided by Adam Smith in the $18^{\text {th }}$ century.

${ }^{2}$ In particular we are referring to the Survey of Manufacturing Technology (1989) and the Survey of Innovation and Advanced Technology (1993).
} 
between the two varies among jobs and over time with changes of technology. However, he also admits that a positive association between education and training is not definitional but is an empirical inference from the observed income data. More schooling, in fact, seems to involve more training, both formal and informal, though not necessarily in a fixed proportion. School education, indeed, is a prerequisite, a basis on which to build additional, more specialized, training. Due to the difficulty collecting data at the firm and the individual level, the empirical evidence is ambiguous. What we do know from the data is that a positive association between education and job training can and has been inferred from differential slopes of experience profiles of wages (Mincer 1984, 1988a, 1988b).

The more recent emphasis on worker training stems from the evidence that a more highly-skilled workforce is needed, and that effective training is closely linked to the workplace and to employer needs. The earnings and employment opportunities of less-educated workers have declined substantially over the last decade. The earning gap between more and less educated workers widened, as did the level of earnings dispersion among workers with the same level of education. These trends have led many researchers to conclude that there has been a steady increase in the demand for skilled workers (Bartel, 1995; Breshanan et al., 2002; U.S. DOL, 1994).

International evidence on the complementary nature of education and training comes also from Brown (1989), Lynch and Black (1995), Brunello (2001) and OECD (2001). Adults with high levels of educational attainment are also more likely to receive more training. On average, three times as many jobrelated training hours are invested in adults with a tertiary qualification compared to those with less than an upper-secondary qualification. Moreover, training tends to reinforce skill differences resulting from an unequal participation in initial education. Participation rates in both job-related continuing education and training and in all continuing education and training rise with levels of educational attainment. Bartel and Lichtenberg (1987) and Lillard and Tan (1986) show that the positive association between initial education and participation in continuing education and training remains strong even after controlling for other characteristics affecting participation in training. Workers tend to receive more training in countries with higher overall average levels of educational attainment, as well as in countries that devote a larger share of GDP to research and development, or that achieve a strong trade performance in "high-tech" industries. These patterns suggest that initial education and continuing education and training are mutually reinforcing, and that education combines with other factors to make adult training least common among those who need it most. Still other empirical support for the complementary nature of education and training comes from Heijke et al. (2003), who find a positive correlation between the level of generic competencies acquired through tertiary education and training participation of young workers. In addition, the amount of on-the-job training needed is positively related to the actual vocational competencies mismatches, as training is needed to adjust the acquired competencies to the required ones.

Human capital theory offers a general answer to why higher-educated workers engage in more training on the job: persons that have greater learning ability and better opportunities to finance the costs of human capital investments, do indeed invest more in all forms of human capital, including 
schooling and job training (Mincer, 1991). Moreover, some analysts claim that school education is a complementary factor to job training in producing human capital: this is in line with the idea that generic competencies acquired in higher education reduce the costs of further learning by providing higher learning abilities for graduates. In other words, education enhances the productivity of job training at work. It is clear, however, that schooling can also be a substitute for job training: thus, the decline in apprenticeship has been attributed to growth in educational levels over the long-run. Finally, both school education and job training are more profitable where productivity growth is more rapid.

\subsection{Stylized facts regarding the link between technology adoption, education and training}

Empirical facts about the link between technical change and education and training can be summarized as follows:

1. a more rapid pace of technology in a sector generates an increased demand for education and training of the sectorial workforce (Bartel and Lichtenberg, 1987). Autor et al. (1998) also show that industries with greater growth in employee computer usage or with more computers per worker have upgraded the skills of their workforce at a faster rate. Increasing use of computer technology, restructuring of business, and a growing global economy are some of the factors economists cite as contributing to changes in the employment structure of the U.S. economy since the early 1980s. Furthermore, there is considerable growth projected to occur in occupations with higher educational requirements; the job classifications that currently use low-skilled workers are experiencing "upskilling," which translates into a need for more responsibility, more knowledge, and ultimately more skill; and, there has been stagnation and even a decrease in the number of jobs that are unskilled or very low skilled (Barnow et al. 1990);

2. more-educated workers are utilized the younger the age of equipment, and this effect is magnified in R\&D-intensive industries (Bartel and Lichtenberg, 1987). In addition countries investing a higher share of GDP in R\&D or having a higher share of researchers in the workforce also tend to have higher training rates and better educated workers (OECD, 1999);

3. there is a greater prevalence of on the job training in sectors in which measures of productivity growth are higher (Lillard and Tan, 1986). Bresnahan et al. (2002) also find that ICT measures, in particular ICT and workplace organization, are correlated with policies for greater investments in human capital, i.e. training and screening of new employees on the basis of their education;

4. over the long run, technologically more progressive industries tend to utilize more-educated workers among the younger workers (Gill, 1988; Bresnahan et al. , 2002; Lopez-Bassols, 2002);

5. the bias of technological change toward human capital means that in the short run, wages of more-educated workers increase more or are reduced less in sectors with more-rapid productivity growth. Thus, wage profiles are steeper in progressive sectors as profitability of training and experience increases (Bartel, 1995; Muysken and Ruholl, 2001); 
6. finally, Lazear (2002) and European Commission (2001) show that students who have a more general curriculum have a higher chance of becoming entrepreneurs, a trend that proxies the successful adoption of new technologies. And that seems to be more frequent in the US - where the emphasis is put on the development of general skills - rather than in Europe - where more vocational-oriented training programmes seem to prevail.

Summarising the points above, education and training are in higher demand where productivity growth is more rapid because the technological changes in production processes that underlie productivity growth, require the training and retraining of workers. Faster technical change requires a faster replacement of skills that become obsolete. This requires more training on the one hand and/or a greater ability to train, i.e. a higher level of education. In fact, if technological change and the relative process of adoption/absorption are in some degree firm-specific, the firm will tend offer training after initially hiring more educated and more-adaptable individuals who, in turn, serve as the 'teachers' making use of the partial non excludability of knowledge.

\subsection{Roundup and basic model features}

Rounding up, there are five important relations between education, training and technological change that we can extract from the theoretical and empirical studies referred to above:

1. The positive link between productivity on the one hand, and training and education on the other;

2. The positive link between high levels of education and R\&D;

3. The positive link between high levels of R\&D and growth;

4. The nature of the interplay between education and training;

5. The nature of the link between high levels of growth (through technical change) and training, i.e. the relative increase in importance of education as a source of growth relative to training in times of fast technical change (Lindbeck and Snower, 2000).

We consider the first two relations to be 'stylised facts' comparable in nature to logical premises. The third point derives from the basic assumptions of R\&Dbased endogenous growth models and is supported by numerous econometric studies. Points 4 and 5 we consider to be relations that should logically follow from the premises 1 to 3 . We use these relations as the basis for the construction of an endogenous growth model that supports our belief that human capital, in the form of not only education but also time-consuming onthe-job training, has a positive impact on innovations' - and thus economic growth. At the same time we think that schooling as a proxy for human capital endowment is not sufficient to describe the process through which workers and firms cope with innovations and rapid technological change. General education is important for making people more 'flexible' in learning specific skills, while on-the-job training is essential in order to reduce the vocational mismatches (Heijke et al., 2003) that new products, new processes and new organizational practices create. In our setting it is technical progress that opens the possibility to have a mismatch between the competencies embodied in individuals through 
schooling and the competencies that firms require in their production processes. Technological change generates new jobs or tasks that, in turn, require new and/or more complex skills: these competencies are not completely acquired through formal schooling, but they can only be learnt and experienced on the job, thus reducing time per worker that can effectively be allocated to the actual production process. Thus, the firm faces a trade-off: by spending resources and time in educating its workforce on the job, the firm, by one side, builds its 'knowledge-base', but, on the other side, it has to spend time out to learn about the new production process associated with new technologies/products. By doing that, it also runs the risk that a new technology will come on-line making the specific competencies just acquired by the workforce rapidly obsolete.

We implement this general trade-off by adopting the links 1-3 listed above, and by considering both formal schooling and on-the-job training as the main channels through which individuals acquire generic and technologyspecific competences. In doing so we will assume that human capital endowments of individuals are a combination of vocational competencies of a particular field of studies and generic competencies. The former includes fieldspecific theoretical knowledge and field-specific knowledge of methods, while the latter includes learning abilities, reflective thinking, problem-solving abilities, analytical competencies, documenting ideas and information.

One of the main assumptions of the model is that the effectiveness by which more-educated workers are able to improve their competencies and their labour productivity is determined by the level of skills acquired during the initial phase of education. A higher level of education is therefore useful in three ways: first, it is the basis for future R\&D activities; second, it positively affects individual labour productivity; third, it allows taking part in training with a higher productivity since higher-educated individuals learn more quickly and are therefore less costly to (re-) train. By modelling the productivity of a worker as a geometric average of his level of education and training, we will effectively be treating these two channels as direct substitutes at the microeconomic level. We will then look at the association between education and training at the macroeconomic level to find out whether we can reproduce stylised fact number 4 , that is somewhat ambiguous in that most material seems to point to a positive, and thus complementary, link between education and training, while some material points to a negative link between education and training, and hence education and training would have to be substitutes, not only at the micro-level, but also at the macro-level. Premises 2 and 3 are covered by using the Romer (1990) model as a template for our own exercise.

The remainder of the article is organised as follows. Section 2 contains a description of the model, including sensitivity analyses that we have performed to show how training and education depend on each other in the framework of intertemporal profit maximisation. We also show how the integration of this training behaviour in a general equilibrium growth setting influences the growth results. Because the model is strongly non-linear, we use numerical simulation to show how it works, and what kind of conclusions can be reached regarding the growth, education and training nexus. Section 3 provides the results of some numerical experiments we have performed with the model, while section 4 includes a summary and some concluding remarks. 


\section{The model}

\subsection{Basic model set-up}

The model combines elements from various endogenous growth models, especially the one by Romer (1990) and Aghion and Howitt (1992). It also uses insights from similar modelling exercises in van Zon and Yetkiner (2003). In order to keep the model as simple as possible, we only have two types of labour as factors of production. The one type of labour is low-skilled ${ }^{3}$ that only has a use in producing output and high-skilled labour that has an alternative use in the form of designing blueprints for new production technologies. There is no capital, so no saving decision needs to be made. The model starts from the assumption that the introduction of a new technology requires the users to learn how to adopt them effectively and efficiently. In order to do that, the workforce associated with a new technology needs to be trained first. ${ }^{4}$ During their training period, the workers are supposed to earn a competitive wage, since they are assumed to be indifferent between working (and so 'earning their keep') and training (thus learning to 'earn their keep' later on). During the training period, workers that are trained are not working; hence they do not produce anything. Therefore, the costs of training include both the direct costs of wages that have to be offered to the trainees and the opportunity costs of not producing anything while training. No direct, fixed or sunk outlays are considered here. The benefits from training are an increased productivity later on during the production phase of a technology. This increase in productivity enables the owners of the firms that use new technologies to economise on wage-costs during the production phase. Training therefore generates costreductions in the future in return for current cost-increases.

Because we assume that there is no production while training, it follows immediately that a model with complete creative destruction of old technologies through the arrival of new technologies is less suited for our purposes, since it would generate 'odd' growth patterns that can not be observed in reality. For, in such a creative destruction setting, the arrival of a new superior technology would lead to a zero level of output, while the workforce is re-trained to be used with the new technology. Instead, a Romer (1990) like approach seems to be more suited, since in that case new technologies do not fully replace old ones, but gradually drive them out of the market. This is the 'creative wear and tear effect' referred to in van Zon and Yetkiner (2003). In such a 'love of variety' setup, old technologies never die, but simply become less important and therefore less used with the progress of time. This creative 'wear and tear' continuously and gradually releases labour resources that can be re-employed by the new firms created with the aim of using the new technologies that arrive on the market.

\footnotetext{
${ }^{3}$ The 'eye-hand coordination' of Romer (1990).

${ }^{4}$ This implies that the know-how of workers with respect to using other technologies is not readily applicable to new technologies. Hence all workers that are assigned to a job need to learn how to perform effectively in that job, through qualifying training, workplace practices training, formal job skills training and so on.
} 
While labour productivity can be increased directly by training, the productivity of the training process is positively influenced by the level of formal education attained by the workforce during the first part of their lives. In addition, we assume that the productivity of researchers is positively influenced by the level of skills they have accumulated through formal schooling.

The set-up outlined above suggests that we may expect an interesting result to arise in which creative 'wear and tear' that is induced by faster arrival of new technologies on the market will lead to shorter payback periods for the training costs involved in absorbing those new technologies. This suggests that faster technological change due to a higher educated population also induces a shift in emphasis from specific training towards more general education (cf. Lindbeck and Snower, 2000). The reason is that a better educated workforce would be more able to adapt to faster changing production circumstances as they would arise from a faster arrival of new technologies. In short, we would expect there to be a premium on formal education rather than specific training in times of rapid technological change. However, we would expect also that an increase in the formal level/duration of education could even result in a reduction of growth because of the increase in 'technology absorption costs' in terms of output foregone during re-training spells that arrive at a faster rate, but may take a shorter time. This suggests that, from growth perspective at least, there may be an optimum level of formal education which would seem to be a result that is very useful from an education policy perspective.

The remainder of this section is organised as follows. In section 2.2 we first pay some attention to the different kinds of labour and their supply. Then in section 2.3 we describe the demand for labour from a micro-perspective as part of our training and production model. In section 2.4 we show how the outcomes regarding optimum training durations and quasi-rents depend on the structural parameters of the model. Section 2.5 describes the aggregate demand for production labour, while section 2.6 describes the demand for R\&D labour. In section 2.7 all the parts of the model are integrated, and since it has become a highly non-linear model, we use numerical simulations to show the main relationships between education, training and economic growth at the aggregate level.

\subsection{Labour supply}

There are two types of labour, low-skilled labour (further called $L$ ), and high-skilled labour (further called $H$ ). $L$ is used in final output production only, while $H$ is used as R\&D labour (further called $H_{R}$ ) or high-skilled production labour (further called $H_{P}$ ).

For reasons of simplicity we will not formulate a fully-fledged overlapping generations model. However, we assume the population to remain fixed, but constantly needing education, as we would expect it to occur in real life too due to the fact that older (educated) generations die, and the youngest are born with a clean educational slate. We will model this by assuming that at any time just a fraction $0 \leq(1-\varphi) \leq 1$ of the high-skilled population is available for final output production and R\&D activities, whereas the complement of that fraction, i.e. $\varphi$, is being educated. To simplify things even further, we assume that $L$ 
does not need any education. ${ }^{5}$ Given the above, we must have that the entire population $P$ is given by:

$P=L+H$

where $H$ is the part of the population that is suitable to fill high-skilled jobs in final output production and in research activities. From the exposition above, it follows immediately that:

$(1-\varphi) \cdot H=H_{R}+H_{P}$

Equation (2) states that the part of the high-skilled population that is not in the educational system is either engaged in R\&D activities $\left(H_{R}\right)$ or in final output production activities $\left(H_{P}\right)$, while $H_{P}$ itself is in part engaged in training $(T)$ and in production $(J)$ :

$H_{P}=T+J$

Equations (2) and (3) reflect the assumption that markets are always clearing, and so there is no unemployment pool that absorbs excess supply. Equation (2) also indicates that educated high-skilled R\&D labour is a perfect substitute for high-skilled production labour, and the other way around.

\subsection{Labour demand}

\subsubsection{The demand for intermediates}

The demand for labour is derived from the assumption that output is produced under perfectly competitive circumstances, by assembling the intermediate outputs of a set of imperfectly substitutable production technologies using low-skilled labour only. We use an Ethier function to describe this final output production process:

$Y=L^{1-\alpha} \cdot \int_{0}^{B} x_{i}^{\alpha} d i$

In equation (4), $Y$ is final output, $B$ is the index of the latest technology that has entered the production phase, and $x_{i}$ is the volume of intermediate output associated with production technology $i .(1-\alpha)$ is the partial output elasticity of low-skilled labour.

For reasons of simplicity, we assume that one unit of each intermediate good requires the use of one efficiency unit of high-skilled labour. Efficiency units of labour used in the production of $x_{i}$ are called $h_{i}$. We therefore have:

$h_{i}=x_{i} \quad \forall \quad 0 \leq i \leq B$

${ }^{5}$ This is a strong assumption, but it reflects the notion that high-skilled workers generally have been educated for far longer periods than low-skilled workers (OECD, 2001). 
We subsequently assume that one physical unit of high-skilled labour associated with technology $i$ (further called $j_{i}$ ) can generate $\pi(s, \varphi)$ efficiency units of labour. The term $\pi(s, \varphi)$ is therefore the productivity of labour, and $s$ measures the length of time spent training by this worker, while $\varphi$ is a direct indicator of the time spent in formal education/schooling. Consistently with human capital theory, we assume $\partial \pi / \partial s>0, \partial \pi / \partial \varphi>0$. We therefore have:

$j_{i}=\frac{h_{i}}{\pi(s, \varphi)}=\frac{x_{i}}{\pi(s, \varphi)} \forall 0 \leq i \leq B$

The demand for each intermediate, given its price $p_{i}$, can be obtained from the first order condition for profit maximisation by the perfectly competitive final output sector:

$p_{i}=\frac{\partial Y}{\partial x_{i}}=L^{1-\alpha} \cdot \alpha \cdot x_{i}^{\alpha-1} \Leftrightarrow x_{i}=L \cdot\left(\frac{p_{i}}{\alpha}\right)^{-\sigma}$

where $\sigma=\frac{1}{1-\alpha}>1$ is the elasticity of substitution between intermediates.

The corresponding demand for labour in physical units can immediately be obtained by substituting (5) and (6) into (7):

$$
j_{i}=\frac{L \cdot\left(\frac{p_{i}}{\alpha}\right)^{-\sigma}}{\pi(s, \varphi)}
$$

Equation (8) represents the derived demand for labour for each intermediate goods producing firm, given the price it sets for its intermediate.

\subsubsection{Maximising the net present value of expected quasi-rents}

The price setting behaviour referred to above, together with the behaviour that determines how long the training period $s$ should be, can be formulated as the solution to the problem of maximising the net present value of the flow of quasi-rents that can be obtained by hiring a population of workers, training them for $s$ time-units, and then using these trained workers to generate output that is sold conditional on the inverse demand curve (7) and its expected evolution over time. For, as we will show later on, in a situation of steady state growth, wages may be expected to grow equally steadily, and so prices (being set using a mark-up over marginal costs) can be expected to grow steadily too.

Because of the symmetry between firms - all firms have the same production technologies and contribute in the same way to final output -, the training period $s$ will be the same for all (relatively) new firms too. Hence, wages are the same for each firm too. We assume furthermore that wages offered to trainees are the same as those for high-skilled workers associated with firms 
that are in their production phase already. The structure outlined above has been depicted in Figure 1.

In Figure 1, the demand for labour to produce an intermediate invented at time $t=0$ is depicted for all moments in time after $t=0$, for a given and constant growth rate of wage. An intermediate comes onto the market after a training phase of duration s. During that phase, the wage rate is assumed to rise at a given proportional rate, and consequently (see equation (8) and (10) further below) the demand for labour at time $t>s$ that is associated with the intermediate invented at time $t=0$, i.e. $j_{t}$, will fall. However, it would be a waste of resources to train more workers than would actually be needed from the start of the production phase at time $s$, hence a rational entrepreneur would hire $j_{s}$ workers during the training phase of the intermediate and then slide down the labour demand curve from the start of the production phase at time $s$.

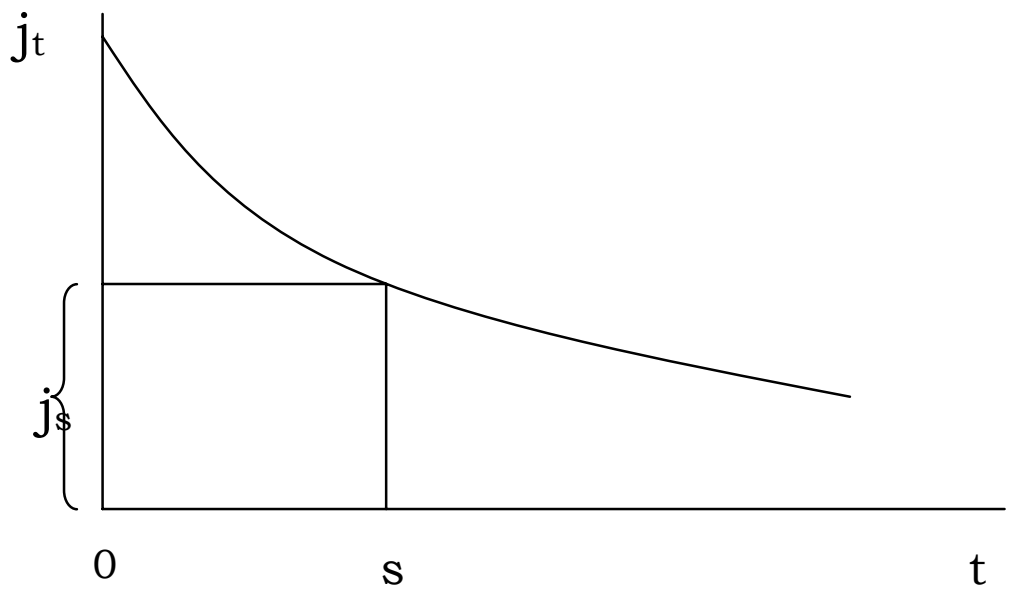

Figure 1

Figure 1 is formalised as follows. One should recall that due to the symmetry between firms, the training period $s$ will be the same for all firms, including new ones. Hence, wages are the same for each firm too. Assuming furthermore that wages offered to trainees are the same as those for high-skilled workers associated with firms that are in their production phase already, the net present value of the expected flow of quasi-rents (further called $Q$ ) for a firm that has bought the latest blueprint at the current time (taken to be time zero), is given by:

$Q=\int_{s}^{\infty} e^{-\rho \cdot \tau}\left\{p_{T} \cdot x_{T}-w_{T} \cdot \frac{x_{T}}{\pi(s, \varphi)} d \tau\right\}-j_{s} \cdot \int_{0}^{s} e^{-\rho \cdot \tau} w_{T} d \tau$ 
where $\rho$ is the rate of discount, and $w_{T}$ is the expected wage rate per physical unit of labour at time $T(T \geq s)^{6}$. In equation (9), where we have used (6) to replace high-skilled labour demand by the demand for intermediates, the first integral describes the flow of quasi-rents, since labour is the only factor of production. That flow starts only after the training-phase has ended and the production-phase has begun. The training-phase takes $s$ units of time. During the training-phase, $j_{s}$ physical units of labour need to be trained, since that is the amount of labour needed when the production-phase starts. There are training costs involved, and the present value of these costs is given by the second integral in (9). The intermediate goods producer now has two independent controls to be determined. The first one is the $Q$ - maximising price of intermediates, and the second one is the $Q$ - maximising length of the training period s. It should be noted that equation (9) can be maximised with respect to the price of intermediates only for the future in as far as it refers to the production phase. ${ }^{7}$ By differentiating (9) with respect to $p_{T}$ for $T \geq s$, we immediately obtain:

$$
\frac{\partial Q}{\partial p_{T}}=x_{T} \cdot\left(1+\varepsilon \cdot\left(1-\frac{w_{T}}{p_{T} \cdot \pi(s, \varphi)}\right)\right)=0 \Leftrightarrow p_{T}=\frac{w_{T}}{[\alpha \cdot \pi(s, \varphi)]}
$$

which is the familiar Amoroso-Robinson price-setting rule, where $\varepsilon=-\sigma=-\frac{1}{1-\alpha}$ is the price-elasticity of the demand for intermediates (see also equation (7)) and where marginal costs are wage costs per efficiency unit of labour. 8

In order to find the $Q$ - maximising value of $s$, we have to use Leibniz's rule for differentiating integrals, since the bounds of both integrals in (9) depend on $s$. We therefore get the first-order condition:

$$
\begin{gathered}
\frac{\partial Q}{\partial s}=0=-\left\{p_{s} \cdot x_{s}-w_{s} \cdot \frac{x_{s}}{\pi(s, \varphi)}\right\} \cdot e^{-\rho \cdot s}-j_{s} \cdot e^{-\rho \cdot s} \cdot w_{s}-\frac{\partial j_{s}}{\partial s} \cdot \int_{0}^{s} w_{\tau} \cdot e^{-\rho \cdot \tau} d \tau \\
-\int_{s}^{\infty} e^{-\rho \cdot \tau} \cdot \frac{\partial\left[w_{\tau} \cdot \frac{x_{\tau}}{\pi(s, \varphi)}\right]}{\partial s} d \tau
\end{gathered}
$$

The first term of (11) within curly brackets is the present value of the loss in quasi-rents that occurs by extending the training-phase by 1 unit of time (marginal opportunity cost of training). The second term is the present value of

\footnotetext{
${ }^{6}$ Note that we have dropped the technology subscripts, because the symmetry of (4) and (5) implies that the net present value problem is essentially the same for all intermediate goods producers.

${ }^{7}$ The price of a good that is not produced and therefore not sold can hardly be regarded as an effective control.

${ }^{8}$ Cf. Aghion and Howitt (1992).
} 
the additional training costs for a given number of trainees associated with a marginal increase in $\mathrm{s}$ (total marginal training costs). The third term is the present value of the increase in total training costs for a change in the number of required trainees that could be expected to occur if the production phase starts 1 unit of time later, i.e. if the training-phase is extended by 1 unit of time (marginal direct cost of training) ${ }^{9}$. The final term represents the present value of the benefits from extra training (marginal training benefit), since these would increase labour productivity and hence decrease production costs for the entire duration of the production phase. Equation (11), indeed, represents the equality condition between marginal benefits and marginal costs of additional training.

In order to find the optimum length of the training phase, it is necessary to specify the productivity function $\pi(s, \varphi)$. In order to keep the analysis as simple as possible and to accommodate the stylised fact that the higher an individual's level of education the faster (s)he learns, so reducing training costs born by firms (Rosen, 1976) we have chosen the following Cobb-Douglas labour productivity-augmenting specification:

$\pi(s, \varphi)=\gamma_{0} \cdot s^{\gamma_{1}} \cdot \varphi^{1-\gamma_{1}}$

where $\gamma_{0}$ and $\gamma_{1}$ are positive and constant parameters and where $0 \leq \gamma_{1} \leq 1$. From equation (12) it is clear that some training and education are always necessary, since otherwise productivity would be zero. One observes that the productivity level of a worker is a geometric weighted average of the worker's educational level, as proxied by $\varphi$, and the level of training as proxied by $s$, where $\gamma_{1}$ is the relative weight or intensity of training in productivity, and $\gamma_{0}$ is a constant scale parameter ${ }^{10}$. Equation (12) shows that a constant level of productivity of a worker can be attained for different combinations of $s$ and $\varphi$, where a decreasing value of $s$ must be compensated by an ever increasing value of $\varphi$ in order to keep productivity constant, and vice-versa. Hence, at the microlevel, education and training are assumed to be (imperfect) substitutes.

\subsection{Sensitivity analysis}

By substituting (10) and (12) into (11), we obtain the equation that can be used to find the optimum value of $s$. Unfortunately, that equation is strongly non-linear which precludes finding a closed form solution for $s$. However, we can get an impression of the sensitivity of the net present value of the quasirents, i.e. $Q$, for changes in $s$ by drawing $Q$ as a function of $s$, for given values of the parameters. These 'base-run' parameter values are given in Table 1 further below. It should be noted that the equation derived above contains (endogenous) variables that are given from the point of view of the individual

\footnotetext{
${ }^{9}$ Indeed, as we will show later on, technical change leads to a continuous upward pressure on wages, and hence to a continuous downward adjustment of the demand for labour. So, by extending the training period, one would normally need less people to train because of the anticipated fall in the demand for labour per technology over time in the steady state.

${ }^{10}$ For instance, we can interpret $\gamma_{0}$ as a proxy of workers' effort while working.
} 
entrepreneur, but that will change endogenously over time in the full model that we will specify later on. Presently, we are only concerned with showing that the specifications we have chosen for the production structure and the productivity function ensure that there is indeed an optimum amount of on the job training that depends in an intuitive way on the parameters listed in the Table below. It should be noted that these parameter values are just some 'fake' numbers not reflecting any empirical regularities, except for their signs.

\begin{tabular}{|cccc|}
\hline Parameter & Value & Parameter & Value \\
\hline$\alpha$ & $\mathbf{0 . 5 0 0}$ & $\hat{w}$ & $\mathbf{0 . 0 2 5}$ \\
\hline$\rho$ & $\mathbf{0 . 0 7 5}$ & $\gamma_{0}$ & $\mathbf{0 . 1 0 0}$ \\
\hline$\gamma_{1}$ & $\mathbf{0 . 1 0 0}$ & $\varphi$ & $\mathbf{0 . 2 5 0}$ \\
\hline $\bar{x}$ & $\mathbf{1 . 0 0 0}$ & $w_{0}$ & $\mathbf{1 . 0 0 0}$ \\
\hline $\mathbf{L}$ & $\mathbf{1 . 0 0 0}$ & $\delta$ & $\mathbf{0 . 5 0 0}$ \\
\hline
\end{tabular}

Table 1. Base-run parameter values

In this Table $\hat{w}$ is the expected instantaneous growth rate of wages, whereas $\rho$ is the rate of discount.11 $\bar{x}$ is a scale factor for the demand for intermediates that will be modelled explicitly later on. For our present illustrative purposes the only thing that is relevant is that it is a constant. $\delta$ is the intrinsic productivity of R\&D workers, which will be made more clear later on.

In Figure 2, the downwards sloping curve is the one associated with $\partial Q / \partial s$. One observes that for the specific parameter set chosen here, $Q$ itself has a maximum, but $Q$ is relatively irresponsive to changes in $\mathrm{s}$ in the neighbourhood of that maximum. The maximum of $Q$ is reached for a value of $s$ about equal to 0.53 .

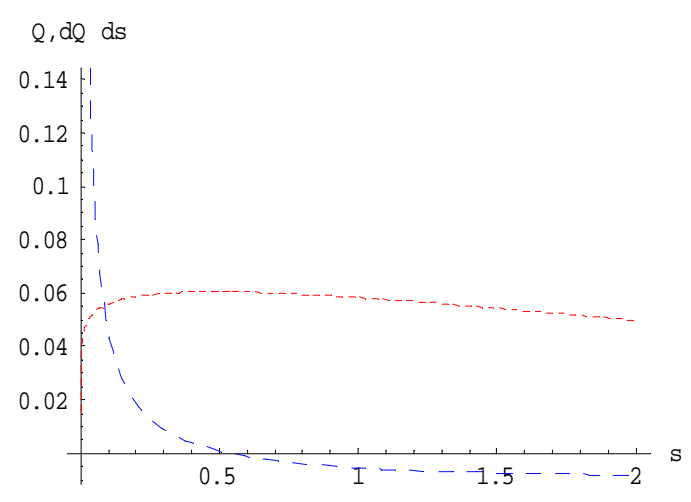

Figure 2

11 Obviously, in the full simultaneous model, the expected growth rate of $w$ will be an endogenous variable. 
By changing the parameters underlying $Q$, we can find out more about the qualitative and quantitative behaviour of $Q$ and the consequences for the optimum value of $s$. In order to do this, we have increased each of the parameters individually by $10 \%$ as compared to its base-run value ${ }^{12}$, and then obtained the corresponding graph of $Q$. The shifts in the graph of $Q$ are a direct indication then of the partial derivatives of $Q$ with respect to the parameter under consideration for the entire range of values of $s$. But rather than showing all the graphs associated with these partial derivatives, we provide information in tabular form below in Table 2. The first column of that Table holds the names of the parameters we have changed, while holding the other parameters constant. The columns labelled $Q$ and $s$ hold information regarding the sign of the partial derivatives of $Q$ and the optimum value of $s$ (hence the shift in the $\frac{\partial Q}{\partial s}$-curve) with respect to the parameter under consideration.

\begin{tabular}{|cccccc|}
\hline Parameter & Q & s & Parameter & Q & s \\
\hline$\alpha$ & - & - & $\gamma_{1}$ & + & + \\
\hline$\hat{w}$ & - & - & $\varphi$ & + & + \\
\hline$\rho$ & - & - & $\bar{x}$ & + & + \\
\hline$\gamma_{0}$ & + & + & $\boldsymbol{w}_{0}$ & - & - \\
\hline
\end{tabular}

Table 2. Parameter sensitivity

From Table 2 we can conclude that the signs of the changes in $Q$ and $s$ are always the same. This indicates that a variation in some parameter changes the shape of the $Q$-curve roughly proportional in all directions measured from the origin. Looking at the effects of individual parameter changes, we see that an increase in $\alpha$ implies an increase of the price-elasticity of demand. This in turn lowers the profit margin, hence profits themselves, hence the present value of the quasi-rents $Q$ too. This will lower the optimum amount of training, as one would expect, ceteris paribus. An increase in the rate of discount $\rho$ has qualitatively the same effects. The present value of the quasi-rents is negatively affected, and so is the optimum amount of training. A rise in the productivity parameter $\gamma_{0}$ raises both the present value of the quasi-rent and the value of the optimum amount of training, again as expected. This fact can open the possibility to test a positive relationship between the effort of workers on the job (see footnote 11) and the amount of training the firm offers them. A rise in $\gamma_{1}$ raises the contribution of training to productivity. It also reduces the contribution of education to productivity. The net effect on the present value of the quasi-rents is positive but very small, while the effect on the optimum

\footnotetext{
${ }^{12}$ The sensitivity analysis has been carried out for $\pm 1 \%$ and $\pm 10 \%$ variations in the parameters' values. In the paper we report only the $+10 \%$ case.
} 
amount of training is distinctly positive. A change in the amount of formal education $\varphi$ has a positive effect on productivity, hence on $Q$. It also raises the optimum amount of training, indicating that the optimizing behavior underlying the choice of the amount of training turns education and training into complements from an observational point of view ${ }^{13}$ rather than the substitutes that they formally are, given the specification of the productivity function we have chosen (cf. (12)). A change in the growth rate of wages reduces $Q$. It also reduces the optimum amount of training, since not only training costs rise during the training phase, but in addition to this, quasi-rents during the production phase will fall. Similar results can be observed for a rise in the initial wage rate. Both $Q$ and the optimum amount of training fall, because profit flows are negatively affected, as with the rise in the expected growth rate of wages. Moreover, the payback period is reduced, thus putting a bonus on starting the production phase earlier than with lower initial wages. Finally, a rise in the autonomous demand for the intermediate under consideration would raise both $Q$ and the optimum amount of training, as one would expect.

We conclude that the sensitivity results are all plausible, but more importantly, the profit maximising behaviour underlying the decision how long to train the workforce turns education and training into observational complements, even though they enter the productivity function given by (12) as direct substitutes.

\subsection{Technological change and the demand for labour at the aggregate level}

As in the Romer (1990) model, a new intermediate input is produced in accordance with the newest blueprint coming from the R\&D sector. The index of the newest blueprint produced at time $t$ is $A(t)$, and R\&D workers produce these blueprints at a proportional rate that is itself proportional to the number of R\&D workers, as in Romer (1990). We therefore have:

$\hat{A}=\frac{d A}{d t}=\delta_{A} \cdot H_{R} \cdot A$

Assuming steady state growth in $\mathrm{A}$ at a rate $\hat{A}$, we should have that the latest intermediate that is actually in the production phase must be the intermediate that has just ended the training phase of length $s$. Let $B(t)$ be the blueprint index of the marginal intermediate just entering the production phase at time $t$. In that case we must have that:

$$
B(t)=A(t-s)=A(t) \cdot e^{(-\hat{A} \cdot s)}
$$

Because of the symmetry of (4) with respect to each intermediate, we must furthermore have that the demand for labour active in the production phase is the same for each intermediate. Hence, the demand for all labour in the production phase must be given by:

\footnotetext{
${ }^{13}$ This holds under the ceteris paribus assumption. Things will change somewhat in the context of the full model, as we will see later on.
} 


$$
J(t)=B(t) \cdot \bar{j}(t)=A(t) \cdot e^{(-\hat{A} . s)} \cdot L \cdot\left[\frac{w(t)}{\pi(s, \varphi)^{\alpha}}\right]^{-\sigma} \cdot \alpha^{2 \sigma}
$$

where $\bar{j}(t)$ is the common number of production workers active on each intermediate with index less than or equal to $B(t)$, and where we have substituted (14) and (8).

Because of technical change, i.e. growth in $A(t)$, we find that, according to equation (15), the demand for labour would grow as fast as $A(t)$ itself, ceteris paribus. For a given level of supply of production labour, this implies that the wage rate is driven up to maintain equilibrium between the demand for production labour and the given supply of production labour. In fact, taking logarithmic time derivatives of (15), while assuming $J(t)$ to be constant, we find that the steady state growth rate of wages must be equal to:

$\hat{w}=\frac{\hat{A}}{\sigma}=\hat{A} \cdot(1-\alpha)$

This positive growth in wages implies that the demand for labour would drop both for intermediates in the production phase, but more importantly, also for labour in the training phase, since we did assume that the workers engaged in technology-specific training must be offered a competitive wage, i.e. the same wage as that of workers in the production phase. However, if the wage rate is expected to rise during the training phase because $A(t)$ grows, then the costefficient amount of labour to hire for the newest intermediate with index $A(t)$ at time $t$ would be $\bar{j}(t+s)$, since that is exactly the amount of production labour that will need to become active after the training phase on intermediate with index $A(t)$ has passed. Something similar happens for all intermediates in the training phase, with an index $i$ such that $B(t) \leq i \leq A(t)$.

Let $\tau(i)$ be the moment in time when the intermediate with index $i$ was invented. Then, in a situation of steady state growth, and assuming $A(O)=1$, we must have that:

$i=e^{[\hat{A} \cdot \tau(i)]} \Leftrightarrow \tau(i)=\frac{\log (i)}{\hat{A}}$

Furthermore, the demand for labour during the training phase would be equal to the number of workers that would be optimal at the time the production phase of intermediate $i$ commences. This amount of labour for intermediate $i$ is given by:

$\bar{j}[\tau(i)+s]=L \cdot\left(\frac{w[\tau(i)+s]}{\pi(s, \varphi)^{\alpha}}\right)^{-\sigma} \cdot \alpha^{2 \sigma}$

\footnotetext{
${ }^{14}$ From equation (17) it is easy to see that the higher the rate of innovation, the earlier the moment in time when a new intermediate is invented.
} 
where $w[\tau(i)+s]$ is the expected wage rate at the time intermediate $i$ enters its production phase. For a given and constant growth rate of wages, we can write:

$$
w\left(t_{1}\right)=w(t) \cdot e^{\left[\hat{[} \cdot\left(t_{1}-t\right)\right]}
$$

Substituting (17) and (19) into (18), we immediately find the demand for labour for intermediate $i$ that is in the training phase at time t:

$$
\bar{j}[\tau(i)+s]=L \cdot\left[\frac{w(t)}{\pi(s, \varphi)^{\alpha}}\right]^{-\sigma} \cdot \alpha^{2 \sigma} \cdot e^{\left[-\sigma \cdot \hat{w} \cdot \frac{(s+\log (i / A))}{\hat{A}}\right]}
$$

We see from (20) that the demand for labour during the training phase depends negatively on the duration of the training period $s$. It also depends negatively on the time of arrival of an intermediate: the younger it is, the longer the period during which training will have to take place, and the lower will be the corresponding demand for labour. Given (19), total demand for labour associated with all intermediates in the training phase can be obtained through integration over all intermediates in the training phase:

$T(t)=\int_{B(t)}^{A(t)} \bar{j}[\tau(z)+s] d z=A(t) \cdot L \cdot \pi(s, \varphi)^{\alpha \sigma} \cdot w(t)^{-\sigma} \cdot \alpha^{2 \sigma} \cdot \hat{A} \cdot e^{(-\sigma \cdot \hat{A})} \cdot\left[e^{\frac{[s \cdot(\hat{A}-\sigma \cdot \hat{w}))-1]}{(\hat{A}-\sigma \cdot \hat{w})}}\right]$

Application of l'Hopital's rule to equation (21) results in:

$T(t)=A(t) \cdot e^{(-\hat{A} . s)} \cdot L \cdot\left(\frac{w(t)}{\pi(s, \varphi)^{\alpha}}\right)^{-\sigma} \cdot \alpha^{2 \sigma} \cdot s \cdot \hat{A}$

Then, using (22) and (15), we find that:

$\frac{J(t)}{T(t)}=\frac{1}{(s \cdot \hat{A})}$

The number of workers in the production phase relative to the number of workers in the training phase falls if the duration of the training period increases, while it also falls if the rate of technical change increases. The latter is easy to understand, since the share of the number of intermediates in the training phase must increase if $\hat{A}$ increases. ${ }^{15}$ Consequently, more people will receive training in times of faster technical change (see stylized facts number 1 , 2 and 3).

15 This share is equal to $(A-B) / A=1-B / A=1-e^{(-\hat{A} \cdot s)}$. For positive s, this share increases with $\hat{A}$. 
We can now obtain the total demand for production labour $\mathrm{H}_{\mathrm{P}}$ both in the production phase and the training phase by adding (15) and (22) together. Then, using (3), we can invert this relation to get the equilibrium wage rate that would clear the market for total production labour both in the training and the production phase:

$$
w(t)=\left\{\frac{A(t) \cdot e^{(-\hat{A} . s)} \cdot L \cdot \pi(s, \varphi)^{\alpha \sigma} \cdot \alpha^{2 \sigma} \cdot(1+\hat{A} \cdot s)}{H_{P}}\right\}^{1 / \sigma}
$$

We see that in the steady state the growth rate of wages would still be given by (16). We also see that an increase in the availability of production labour would depress wages, as we would expect. At this stage a deeper analysis is not possible since $s$ itself, but also $\hat{A}$ (see section 2.6 below), depends (non-linearly) on wages and wage growth. However, in section 3 we will use (24) as part of a system of simultaneous relations to find out about the connection between education, on-the-job training, technology adoption, production and innovations' growth at the aggregate level. Before doing that, however, we must describe the demand for R\&D labour.

\subsection{The demand for R\&D labour}

In this section, we slightly amend the R\&D production function that Romer (1990) has used, in that we take into account the productivity effects of education on the direct productivity of high-skilled R\&D workers. In fact, we assume for simplicity that this productivity effect is equally strong in production and in R\&D activities. So we include the term $\varphi^{1-\gamma_{1}}$ as we did in the productivity equation given by (12). We therefore have:

$\hat{A}=\& 4=\delta_{A} \cdot H_{R} \cdot \varphi^{1-\gamma_{1}}$

As usual a dot over a variable denotes its time-derivative. Assuming, as Romer does, that the present value of the expected quasi-rents can be captured by the blueprint producers, and that $R \& D$ wages equal the marginal benefits from hiring an additional $R \& D$ worker, we find an expression for the $R \& D$ workers' wage rate:

$w_{R}=\frac{\partial \&}{\partial H_{R}} \cdot Q=Q \cdot A \cdot \delta_{A} \cdot \varphi^{1-\gamma_{1}}$

Substituting (9) for $Q$ as well as (10) for all the intermediates that are in the production phase ${ }^{16}$, we find a complicated expression for the wage rate for $R \& D$ workers that depends on the wage rate of production workers. When we substitute (24) into that expression, we can find out the value of $H_{P}$ as a function of all the variables and parameters of the model, for which wages for the high-skilled workers earned in both their uses (as R\&D and as production

${ }^{16}$ We assume that there is no output, hence no sales, on intermediates during the training phase. 
workers) are equal. Because of the possibility of labour market arbitrage, the latter is an equilibrium condition. Hence, we get:

$$
H_{P}=-\frac{e^{[s(-\hat{A} / \sigma+\rho)]} \cdot(1+\hat{A} \cdot s) \cdot \alpha \cdot\left(-\frac{\hat{A}}{\sigma}+\rho\right) \cdot(\alpha \cdot \hat{A}+\rho) \cdot \varphi^{\gamma_{1}-1}}{\delta_{A} \cdot\left[\hat{A} \cdot(1-2 \alpha)-\rho+e^{\left[s\left(-\frac{\hat{A}}{\sigma}+\rho\right)\right]} \cdot \alpha \cdot(\alpha \cdot \hat{A}+\rho)\right]}
$$

This equation is hard to interpret, since we still need to substitute for $\hat{A}$ using (25) but also for $s$, and subsequently equation (2) to obtain the final solution for $H_{P}$. Indeed, substituting (2) into (25), we get:

$$
\hat{A}=\left[(1-\varphi) \cdot H-H_{P}\right] \cdot \delta_{A} \cdot \phi^{1-\gamma_{1}}
$$

The simultaneous solution to (27) and (28) is highly non-linear and it does not have a closed form; this forces us to investigate the properties of our model in a numerical/graphical way. This is done in the next section.

\section{The full model: some numerical simulation results}

The simultaneous model that we are going to solve numerically for the variables $s, \hat{A}, H_{P}, H_{R}, J, T$ consists of the following equations:

1. equation (16) that describes the link between technical change and wage growth;

2. equation (27) that describes the equilibrium level of production labour demand;

3. equation (28) that describes the rate of technical change in function of the level of production labour;

4. equation (23) that describes the ratio of production labour in the production phase relative to production labour in the training phase;

5. equation (2) that describes the constraint on the use of high-skilled labour as R\&D workers and production workers;

6. equation (3) that describes the requirement that each production worker must either be producing or be training at any point in time.

We now put the productivity parameter associated with the R\&D production function (28), i.e. $\delta_{A}$, equal to 0.5 and then solve the simultaneous model for varying values of $\varphi$, i.e. the level of education of high-skilled workers proxied by the duration of formal education, whereas the other parameters still have the values shown in Table 1, except for the growth rate of wages that is now linked to the rate of technical change through equation (16), and $\bar{x}$, that is given by the parameter combination $\bar{x}=L \cdot \alpha^{\sigma}$ (cf. equation (7)). The way in which the equilibrium steady state growth rate $\hat{A}$ depends on the amount of education can now readily be observed from solving the simultaneous system outlined above, for all values $0 \leq \varphi \leq 1$. The result is presented in Figure 3 . In this figure, we find two curves with an 'inverted' U-shape. The solid curve is the one associated with a value of $\delta=0.5$, whereas the dotted curve is associated with a 
value of $\delta=0.6$. The vertical axis of figure 3 below is associated with the growth rate of $A$, indicated by $G A$.

Looking at this figure, there are two main conclusions to be drawn. First of all, the rate of technical change depends positively on the value of the productivity parameter $\delta_{A}$, since the dotted curve lies entirely above the solid curve. Secondly, from a growth perspective, there seems to be an optimum value of the level of education, since the growth curve reaches a definite maximum for $\varphi \approx 0.43$. The reason why the curve has an inverted U-shape is the following: if an individual spends all his/her time at school, (s)he does not produce output. If an individual spends no time at all at school, on the contrary, (s)he does not get trained enough to produce; this follows immediately from (28).

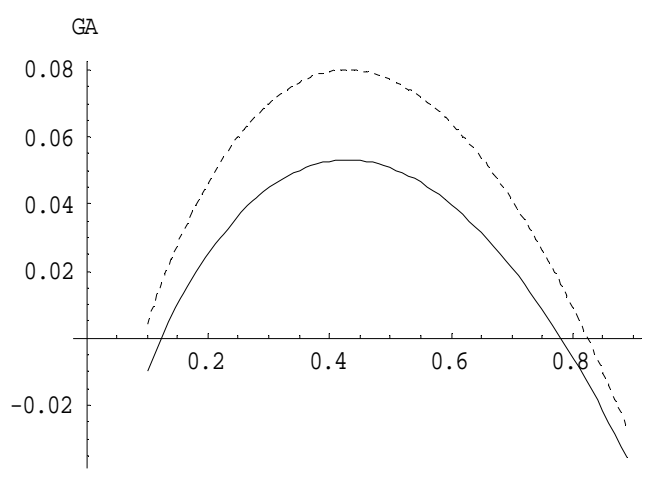

Figure 3

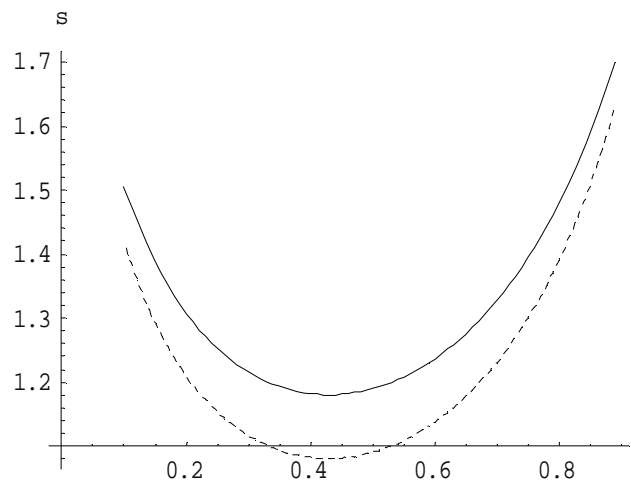

Figure 4

We have also plotted the corresponding graphs for the duration of training $s$, as shown in Figure 4. This graph shows that for low levels of education, an increase in the level of education will be associated with a lower level of training, suggesting that training and education act like substitutes. For high levels of education, however, the amount of training rises with the level of education itself, suggesting that education and training act like complements. This result is consistent with the mixed results we have found in the introductory part regarding the complementarity/substitutability of training and education in function of the level of education. However, we still have to explain the downward sloping part of the curves, since our partial sensitivity results on the link between the duration of training and education was positive. Concerning this, we should recall that on the downward sloping part of the curve in figure 4, the rate of technical change is rising, as we can see from figure 3, and therefore also the growth rate of wages (cf. equation (16)). Table 2, that contains our partial sensitivity results, shows that an increase in the growth rate of wages reduces the optimum amount of training, because profit flows are strongly eroded. On the downward sloping part of the training duration curves above, the rise in the growth rate of wages causes training levels to fall by more than the optimum amount of training expands with an increase in the level of education. When the rate of technical change starts falling again after $\varphi$ starts exceeding its growth maximising value, the growth 
rate of the wage rate is reduced as well, and the partial complementarity results become stronger again, resulting in the observed positive correlation between education and training for higher levels of education. Interestingly, this downward shift of the training duration curve signals that in times of strong technical change, general education becomes a relatively more important determinant of productivity than technology specific training, since for every level of general education, the optimum level of training falls.

Figure 5 shows how the number of $R \& D$ workers changes with the level of education. Again, this is as expected: at first the number of R\&D workers rises for an increase in the level of education, and then it falls when the reduction in available hours per R\&D worker falls below the increase in the absolute productivity of that worker. Since the direct impact of education on $R \& D$ productivity is subject to diminishing returns, the hours-reduction effect will start to outweigh the positive productivity effect for values of the levels of education above $\varphi=\left(1-\gamma_{1}\right) /\left(2-\gamma_{1}\right)$.

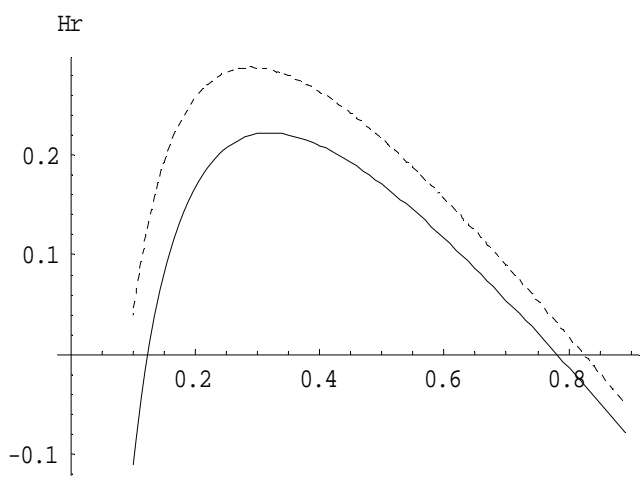

Figure 5

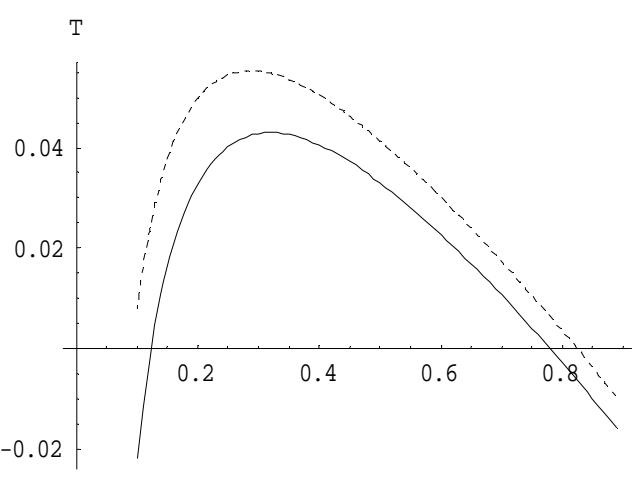

Figure 6

In Figure 6, we depict what happens to the number of workers in the training phase. The results are very interesting on two accounts. First, an increase in the productivity of R\&D workers raises the number of production workers in the training phase. This is consistent with the idea that increased technical progress brings about stronger 'creative wear and tear' of technology specific knowledge, requiring more people to be retrained. Secondly, the number of people in the training phase peaks at levels of education that are somewhat lower than in the low productivity/growth case. This is due to the fact that the strong upward pressure on wage growth for low but growing levels of education have a strongly negative effect on the duration of training (see Figure 4) that leads to a fall in the number of people in the training phase even before the peak in the rate of technical change itself has been reached.

\section{Summary and Conclusions}

In this paper we have presented a simple model that integrates training decisions at the micro-level with education decisions at the macro-level in an 
endogenous growth setting. Our model is constructed to explain the observed link between training, education and technical change through the incorporation of a number of stylised facts regarding training, education and new technology adoption by firms. Based on these stylised facts, we want to be able to investigate: i) the nature of the interplay between education and on-thejob training, and ii) the nature of the link between innovations' growth performance on the one hand and the relative importance of general education and technology-specific training on the other.

The training decisions referred to above are part of a set-up where new intermediate goods are continuously invented in a 'love of variety' production model in which low-skilled workers use intermediates to produce final output in a completely standardised production process. The intermediates on the other hand require the input of high-skilled human resources. Because of the specialised character of the intermediates, these high-skilled workers need to learn how to produce these new intermediate goods. In order to do that, they first enter an implicitly successful training phase before entering the production phase. During the training phase, production workers do not produce anything, or we can think they produce a so little amount of output that can be supposed to be closed to zero. Thus, an intertemporal trade-off arises for the employers: in fact, the training process itself increases the productivity of the trainees, so that cost-savings for the firm in the future can be realised. In the meantime, employers will have to offer a competitive wage to the trainees, since the latter have the option of working in other firms that are already in the production phase, earning the competitive wage. We show that when employers are maximising the stream of quasi-rents associated with producing intermediate goods, there is an optimum duration of training.

With respect to the productivity increase through training, we assume that that is positively affected by the level of education of a trainee: a high level of education makes it relatively easy to adopt new, technology-specific, knowledge. This is consistent with the stylised facts. So, from a productivity point of view, the level of education and the amount of training are assumed to be indirect substitutes. When we analyse the firm's quasi-rents maximization problem, we find that if the level of education increases then the optimum amount of training increases as well, which is consistent with most of the empirical evidence presented in the introduction of the paper. This observational complementarity comes from the fact that for a rise in the level of education, a corresponding rise in the level of training requires relatively little extra-costs, whereas, ceteris paribus, the period during which the resulting cost savings can be realised can be relatively long. This result confirms the empirical evidence that consider formal education and employer-based training as mutually reinforcing factors in the process of competence building. We then complete the general equilibrium growth model by adding an R\&D sector as in Romer (1990), where we introduce the level of education as a factor that determines the productivity of high-skilled R\&D workers in the same way as that of high-skilled production workers. In addition to this, since time spent on education cannot be spent either as production time or R\&D-time there is also a negative impact of the increase of the educational level on the availability of high-skilled R\&D time. This defines an inverted U-shaped relationship between the rate of technical change, as captured by the rate of growth of the number of intermediates, and the level of education. We close the model by aggregating 
over all technologies to obtain aggregate demand being the sum of production labour for all technologies in their production phase and in their training phase, when applicable, and $R \& D$ labour. We then solve the aggregate rate of technical change, aggregate production labour demand, aggregate demand for labour in the training phase and aggregate R\&D labour demand for an exogenously given level of education. We then increase the productivity parameter associated with the $R \& D$ process to see what a higher rate of technical change means for the variables under consideration. We find that this does indeed raise both the number of R\&D workers and the rate of technical change, as expected. We also find that the observational complementarity between education and training turns into a U-shaped relationship between the duration of training and the level of education, indicating observational substitutability for low levels of education and complementarity for higher levels of education. This observational substitutability arises from a general equilibrium effect, that pushes up wages as the rise in the level of education raises the growth rate of the economy and hence the demand for production labour. This reduces the optimum duration of training, as was shown in the parameter sensitivity results. We also observe that this U-shaped curve shifts downward in the training and education-plane when technological change speeds up, thus changing the training and education mix in favour of general education in times of faster technical change. We find furthermore that the rate of technical change peaks for a certain level of education, indicating that there is a growth maximising level of education.

We conclude that our model, that uses standard constructs from new growth modelling, reproduces the mixed findings regarding the substitutability and complementarity between education and training. Our model also indicates that there is a socially optimal level of education (and training) that implicitly defines a socially optimal level of the human capital stock. Furthermore, the inverted U-shape we find for the relationship between the growth rate of innovations and the level of education confirms the results previously achieved by the neo-Schumpeterian growth literature (cf. Aghion and Howitt, 1998).

Finally, our model shows that in times of increasing technical change, the optimum 'portfolio- mix' between education and training changes in favour of the former, since that provides a relatively solid basis for the development of technology- specific skills that are prone to creative destruction. 


\section{References}

Acemoglu D. (1996), Training and innovation in an imperfect labour market, Review of Economic Studies, Vol. 64, pp. 445-464.

Acemoglu D. (2002), Technical change, inequality, and the labor market, Journal of Economic Literature, Vol. 40, march, pp. 7-72.

Aghion P. and Howitt P. (1992), A model of growth through creative destruction, Econometrica, Vol. 60, pp. 323-351.

Aghion P. and Howitt P. (1998), Endogenous growth theory, Cambridge, MIT Press.

Antonelli G. and Maggioni M.A. (1997), Formazione, competenze e lavoro in contesti economici in rapida evoluzione, in Terna P. (eds), La formazione e il lavoro al tempo delle reti telematiche, Turin, Rosenbeg \& Sellier.

Autor D., Katz L. and Krueger A. (1998), Computing inequality: have computers changed the labour market?, Quarterly Journal of Economics, Vol. 63, pp. 11691214.

Barnow B.S., Chasanov A.B. and Pande A. (1990), Financial incentives for employer-provided worker training: a review of relevant experience in the U.S. and abroad, Washington, DC, Urban Institute Policy Memorandum.

Barro R.J. and Sala-I-Martin X. (1995), Economic growth, New York, Mc Graw Hill.

Bartel A., Ichiniowski C. and Shaw K. (2003), The effects of recent technological change on skill demand: an analysis using direct intra-industry measures, NBER Working Papers, January.

Bartel A. and Lichtenberg F. (1987), The comparative advantage of educated workers in implementing new technology, Review of Economics and Statistics, Vol. 69, No. 1, February.

Bartel A. (1995), Training, wage growth, and job performance: evidence from a company database, Journal of Labour Economics, Vol. 13, No. 3, pp. 401-425.

Bresnahan T., Brynijolfsson E. and Hitt L.M. (2002), Information technology, workplace organization, and the demand for skilled labor: firm-level evidence, Quarterly Journal of Economics, February.

Brown C.C. (1989), Empirical Evidence on Private Training, Investing in People, background papers of the Commission on Workforce Quality and Labor Market Efficiency.

Brunello G. (2001), On the complementarity between education and training in Europe, IZA Discussion Paper, Vol. 309, IZA, Bonn, pp. 1-38. 
David P. A. (1990), The dynamo and the computer: an historical perspective on the modern productivity paradox, American Economic Review, vol. 80(2), may, pp. 355-361.

European Commission (2001), European Competitiveness Report 2001.

Frazis H.J., Herz D.E., and Horrigan M.W. (1995), Employer-Provided Training: Results from a New Survey, Monthly Labor Review (May), pp.3-17.

Gander J.P. (2002), Technology adoption and labor training under uncertainty, Economics of Education Review, Vol. 22, Issue 3, pp. 285-289.

Gill I. (1988), Technological change, education and obsolescence of human capital, University of Chicago, paper prepared for NBER Summer Institute.

Goldin C. and Katz. L.F. (1998), The origins of technology-skill complementarity, Quarterly Journal of Economics, 113, pp. 693-732.

Greenwood J. and Yorukoglu M. (1997), 1974, Carnegie-Rochester Conference Series on Public policy, Vol. 46 (June), pp. 49-95.

Haltiwanger, Manser, and Topel, (eds.), Labor Statistics Measurement Issues, Chicago, IL, University of Chicago Press.

Heijke H., Meng C. and Ris C. (2003), Fitting to the job: the role of generic and vocational competencies in adjustment and performance, Labour Economics, Vol. 10(2), April, pp. 215-229.

Helpman E. (1998), General purpose technologies and economic growth, Cambridge, MIT Press.

Helpman E. and Trajtenberg M. (1998a), Diffusion of general purpose technologies, in Helpman E. (eds), General purpose technologies and economic growth, Cambridge, MIT Press.

Helpman E. and Trajtenberg M. (1998b), A time to sow and a time to reap: Growth based on general purpose technologies in Helpman E. (eds), General purpose technologies and economic growth, Cambridge, MIT Press.

Helpman E. And Rangel A. (1999), Adjusting to new technology: experience and training, Journal of Economic Growth, Vol. 4, pp. 359-383.

Kalaitzidakis P. (1997), On-the-job training under firm-specific innovations and worker heterogeneity, Industrial Relations, Vol. 36, n. 3, july, pp. 371-390.

Krueger D. and Kumar K.B. (2002), Skill specific rather than general education: a reason for US-Europe differences?, NBER Workinp Paper9408.

Lazear E.P. (2002), Entrepreneurship, NBER working paper n. 9109. 
Lillard L. and Tan H. (1986), Training: Who gets it and what are its effects, Rand Corporation, R-3331-DOL, March.

Lindbeck A. and Snower D. (2000), The division of labour and the market for organizations, Research Institute of Industrial Economics, working paper n. 557, may.

Lynch L. M. (1995), A Needs Analysis of Training Data: What Do We Want, What Do We Have, Can We Ever Get It?, in Haltiwanger, Manser, and Topel, (eds.), Labor Statistics Measurement Issues, Chicago, IL, University of Chicago Press.

Lynch L. M. and Black S.E. (1995) "Beyond the Incidence of Training: Evidence from a National Employers Survey." NBER Working Paper n. 5231.

Lopez-Bassols V. (2002), ICT skills and employment, OECD-STI Working Papers n. 10, OECD, Paris.

Mincer J. (1962), On-the-job training: costs, returns, and some implications, Journal of Political Economy, vol. 70, part 2, pp. 50-79.

Mincer J. (1984), Human capital and economic growth, Economics of Education Review, vol. 3, pp. 195-205.

Mincer J. (1988a), Job training, wage growth, and labor turnover, Unpublished NBER Working Paper, in Mincer J. (1993), Studies in human capital - Volume 1, Edward Ellgar.

Mincer J. (1988b), Job training: costs, returns, and wage profiles, paper presented at Conference on Job Training, Madison, Wisconsin; revised version published in Ritzen J.H.H. and D. Stern (edt) (1991), Market failure in job training, Springer Verlag.

Mincer J. (1989), Human capital responses to technological change in the labour market, paper presented at Conference on Economic Growth, SUNY, Buffalo, in in Mincer J. (1993), Studies in human capital - Volume 1, Edward Ellgar.

Mincer J. (1991), Education and unemployment, Unpublished NBER Working Paper No. 3838, in Mincer J. (1993), Studies in human capital - Volume 1, Edward Ellgar.

Mincer J. (1993), Studies in human capital - Volume 1, Edward Ellgar.

Muysken J. and Ruholl (2001), The impact of education and mismatch on wages: the Netherlands, 1986-1998, MERIT-Infonomics Research Memorandum Series, No. 030, Maastricht, The Netherlands.

Nelson R. and Phelps E. (1966), Investment in humans, technological diffusion and economic growth, American Economic Review, n 61, pp. 69-75. 
OECD (1999), Employment Outlook, OECD, Paris.

OECD (2001), Education at a glance: OECD indicators 2001, OECD, Paris.

OECD (2003). Employment Outlook, OECD, Paris.

Parsons D.O. (1990), The firm's decision to train, Research in Labor Economics, Vol. 11, pp. 53-75.

Pencavel J.H. (1972), Wages, specific training, and labor turn-over in US manufacturing industries, International Economic Review, Vol. 13, pp. 53-63.

Pischke, J. S. (2001), Continuous training in Germany, Population and Economics, Vol. 14, pp. 523-548.

Romer P.M. (1990), Endogenous technological change, Journal of Political Economy, Vol. 98, pp. 71-103.

Rosen S. (1976), A theory of life earnings, Journal of Political Economy, vol. 84(4), pp. 44-67.

Terna P. (eds), La formazione e il lavoro al tempo delle reti telematiche, Torino, Rosenbeg \& Sellier.

U.S. Department of Labor (1996), Involving employers in training: literature review, Employment and Training Administration: http://www.doleta.gov/wtw/documents/bestpractice/reportlit.cfm\#N_1_

van Zon A. and Yetkiner I.H. (2003), An endogenous growth model with embodied energy-saving technical change, Resource and Energy Economics, n. 25, pp. 81-103. 